\title{
Effects of Holding Beta-Blockers on the Vital Signs of Heart Failure Patients
}

\author{
Marc Ericksonª, b, Kimberly O’Della, Juan Carlos Malpartida ${ }^{\mathrm{a}}$, Jacob Mok ${ }^{\mathrm{a}}$, \\ Rafay Khan ${ }^{\mathrm{a}}$, Dharmendra Patel ${ }^{\mathrm{a}}$
}

\begin{abstract}
Background: Heart failure with reduced ejection fraction (HFrEF) is associated with recurrent hospitalizations and high mortality. Guideline-directed medical therapy (GDMT) reduces morbidity, mortality and re-admission rates. Despite the evidence, less than $50 \%$ of patients with HFrEF are prescribed appropriate medical therapy. When hospitalized patients have these medications discontinued on admission or during hospitalization, they are less likely to have them restarted on discharge. The goal of this study was to determine the incidence of disruption of beta-blocker (BB) therapy during hospitalization for HFrEF patients admitted to an academic tertiary referral hospital.
\end{abstract}

Methods: We conducted a retrospective study in a single teaching hospital over the course of 1 year, and utilized data queried from the electronic medical record (EPIC) database. Inclusion criteria were met by patients with an ICD-10 code diagnosis of heart failure, left ventricular ejection fraction less than $40 \%$ and $\mathrm{BB}$ prescription prior to admission. Additional information noted included age, sex, vital signs throughout the admission and dates where BB was not given for a full 24-h period. Patients in the intensive care unit (ICU) were excluded due to uncertainty of their hemodynamics. Data were extracted from the electronic medical record database and analyzed through Python, Microsoft Excel and RStudio. The incidence of BB disruption during hospitalization was defined as a 24 -h period where no $\mathrm{BB}$ was administered. Blood pressure (BP) and heart rate (HR) levels were compared between patients who received $\mathrm{BB}$ and patients who had a disruption in their BB. Measurements were also obtained to assess whether a correlation exists between holding BB therapy and time of the year, age, or sex.

Results: Between January 2018 and January 2019, 780 patient encounters met inclusion criteria for the study. Patients who were continued on BB therapy had an average BP of $120.8 / 68.7 \mathrm{~mm} \mathrm{Hg}$ and

Manuscript submitted September 21, 2020, accepted October 6, 2020

Published online December 11, 2020

aDepartment of Cardiology, University of Tennessee at Chattanooga, $975 \mathrm{E}$ 3rd Street, Chattanooga, TN 37403, USA

${ }^{b}$ Corresponding Author: Marc Erickson, Department of Cardiology, University of Tennessee at Chattanooga, 975 E 3rd Street, Chattanooga, TN 37403 , USA. Email: MDErickson89@gmail.com

doi: https://doi.org/10.14740/cr1169 an HR of $82.4 \mathrm{bpm}$ on days they received their BB. Patients who had a disruption of BB therapy had an average BP of 117.7/67.6 mm Hg and an HR of $88.6 \mathrm{bpm}$ on the days of the disruption $(\mathrm{P}<0.001)$. There was no association between holding $\mathrm{BB}$ and age, sex, or time of year.

Conclusions: This study showed that in an academic tertiary referral center, patients with HFrEF who are not in an ICU have a $23 \%$ chance of not receiving their recommended BB therapy for $24 \mathrm{~h}$. While the differences measured for BP and HR are statistically significant, they are not clinically significant.

Keywords: Heart failure; HFrEF; Beta-blockers

\section{Introduction}

Heart failure is associated with high healthcare resource utilization, high mortality and high morbidity. Patients with an ejection fraction less than or equal to $40 \%$ have been shown to have reduced morbidity and mortality with the initiation of guideline-directed medical therapy (GDMT). Multiple seminal trials have shown mortality benefits of beta-blocker (BB) use in heart failure with reduced ejection fraction (HFrEF) patients, first with bisoprolol and metoprolol succinate in the CIBIS-II and MERIT-HF trials of 1999, respectively, later joined by carvedilol in the COPERNICUS trial of 2002 [1-3]. More recently, the BB-META-HF Study showed that BBs significantly reduce mortality in HFrEF patients with moderate to severe kidney dysfunction [4]. The ACCF/AHA Guidelines for the Management of Heart Failure include class I recommendations for the use of the aforementioned BBs in stage $\mathrm{B}$ and $\mathrm{C}$ HFrEF patients for the reduction of mortality, as well as the continuation of GDMT in hospitalized HFrEF patients. Furthermore, these guidelines promote the maximally tolerated doses of medication to achieve neurohormonal blockade [5, 6]. Despite the evidence showing the benefits of GDMT [1-3, $7,8,9-11]$, less than $20 \%$ of patients are prescribed optimal GDMT at appropriate doses [12].

In the inpatient setting, optimization of GDMT can be achieved with close monitoring in a controlled environment. This can be achieved by internists, hospitalists, family medicine physicians, or cardiologists. Obvious hurdles to optimization of GDMT in this setting are administrative pressures to 
reduce hospital duration and acute illness compromising the ability to up-titrate these medications appropriately [13]. Lack of nursing familiarity with HFrEF can result in holding these medications out of concern for precipitating iatrogenic cardiogenic shock. Despite previous studies showing minimal effects of BBs on blood pressure in heart failure patients, this represents a significant concern for nursing staff $[12,14,15]$. We sought to evaluate these concerns by investigating the differences in blood pressure on days where BBs were held versus days BBs were provided to patients with HFrEF.

\section{Materials and Methods}

\section{Study design}

This was a retrospective cohort study conducted at a single tertiary care center between January 2018 and January 2019. Our primary objectives were to determine the hold rate of $\mathrm{BBs}$ in patients with heart failure who had previously been on $\mathrm{BBs}$ and to determine the difference in vital signs between days $\mathrm{BBs}$ were given versus days $\mathrm{BBs}$ were held. A BB was considered held for that day if no BBs were administered in a 24-h period. If even one dose was given that day, it was considered a day in which the patient received therapy. Secondary objectives were to determine the length of hospital stay and to assess any differences in hold rates based on pharmacologic agent, age, month and gender. This study was approved by the Institutional Review Board at Erlanger. This study was conducted in compliance with the ethical standards of the responsible institution on human subjects as well as with the Helsinki Declaration.

\section{Data collection}

Data were collected from the electronic medical record (EMR) (EPIC) through secure data request. Patients were identified by an admission date between January 2018 and January 2019 along with a history of heart failure as identified by any associated ICD-10 code. The broad nature of this ICD-10 (I50) code necessitated a manual verification of patient status as "heart failure with reduced ejection fraction". From this cohort, we acquired all vital signs during admission, the timing of the vital signs, age of the patient at time of admission, gender, type of $\mathrm{BB}$ prescribed and specific dates where BB therapy was held for $24 \mathrm{~h}$. For BBs dosed more than once a day, all doses had to be missed to be considered a missed date.

\section{Limitations}

This model of data collection presents a new and novel way to rapidly collect data; however, it does lack specificity. The goal is to leverage large volumes of raw data to improve the signalto-noise ratio in order to prove that further research would be fruitful. Our EMR does not mandate providing a rational why medications are held, therefore we only have the reported vitals proximal to the event. Different providers input their diagnoses to varying specificities, and these may not be recorded in a way that is explicitly searchable. This limits our ability to stratify patients based on co-morbidities. The history of HFrEF was investigated manually; however, the degree of severity was not reported in a universal way, such as with $5 \%$ increments estimated. While we know what medications were prescribed during the hospitalization, it is readily available which dosage was held on a given day. These limitations in specificity reduce our ability to establish a causal link. Future studies will be able to investigate these more specific questions. Future studies will also use more advanced post processing methods to rule out outlier data points.

\section{Data analysis}

Data were analyzed using a combination of software packages including Python (general data formatting) and RStudio (data analysis). Continuous variables were compared utilizing the Welch's paired $t$-test. P values less than 0.05 were considered significant.

\section{Results}

\section{Patient characteristics}

Between January 2018 and January 2019, 780 patients (539 men and 241 women) were identified who met our inclusion criteria of being admitted to Erlanger main campus, with a total of 927 hospital admissions in that time span. Patients had a slightly higher mean systolic blood pressure on days where they received $\mathrm{BB}$ therapy compared to when they did not (120.5 $\mathrm{mm} \mathrm{Hg}$ vs. $117.6 \mathrm{~mm} \mathrm{Hg}, \mathrm{P}<0.001$ ) (Fig. 1), a slightly higher diastolic blood (68.7 mm Hg vs. $67.6 \mathrm{~mm} \mathrm{Hg}, \mathrm{P}<0.001)$ (Fig. $2)$ and a slower heart rate $(82.4 \mathrm{bpm}$ vs. $88.6 \mathrm{bpm}, \mathrm{P}<0.001)$ (Fig. 3) (Table 1). The mean duration of stay for patients on carvedilol and metoprolol was 7.02 and 8.8 days, respectively $(\mathrm{P}<0.05)$ (Fig. 4). There was no difference associated with age or gender (Figs. 5 and 6). The average hold rate of BBs for any given day in a year was $23 \%$ (Fig. 7 ).

The data indicate that there is no clinically significant difference in the blood pressures of these patients on a day-today basis. These findings are consistent with previous findings that cardiac remodeling occurs over the span of months. This information confirms clinical intuition that BBs should not be held purely on blood pressure as there is no meaningful difference in blood pressure on the days the BBs were held. BBs should only be held for symptoms. Changes in blood pressure throughout the day were more consistent with diurnal rhythms than a consistent effect of medication (Fig. 8).

\section{Discussion}

In patients over the age of 65 years, heart failure is the leading cause of hospitalization [16], while hospitalization drives the 


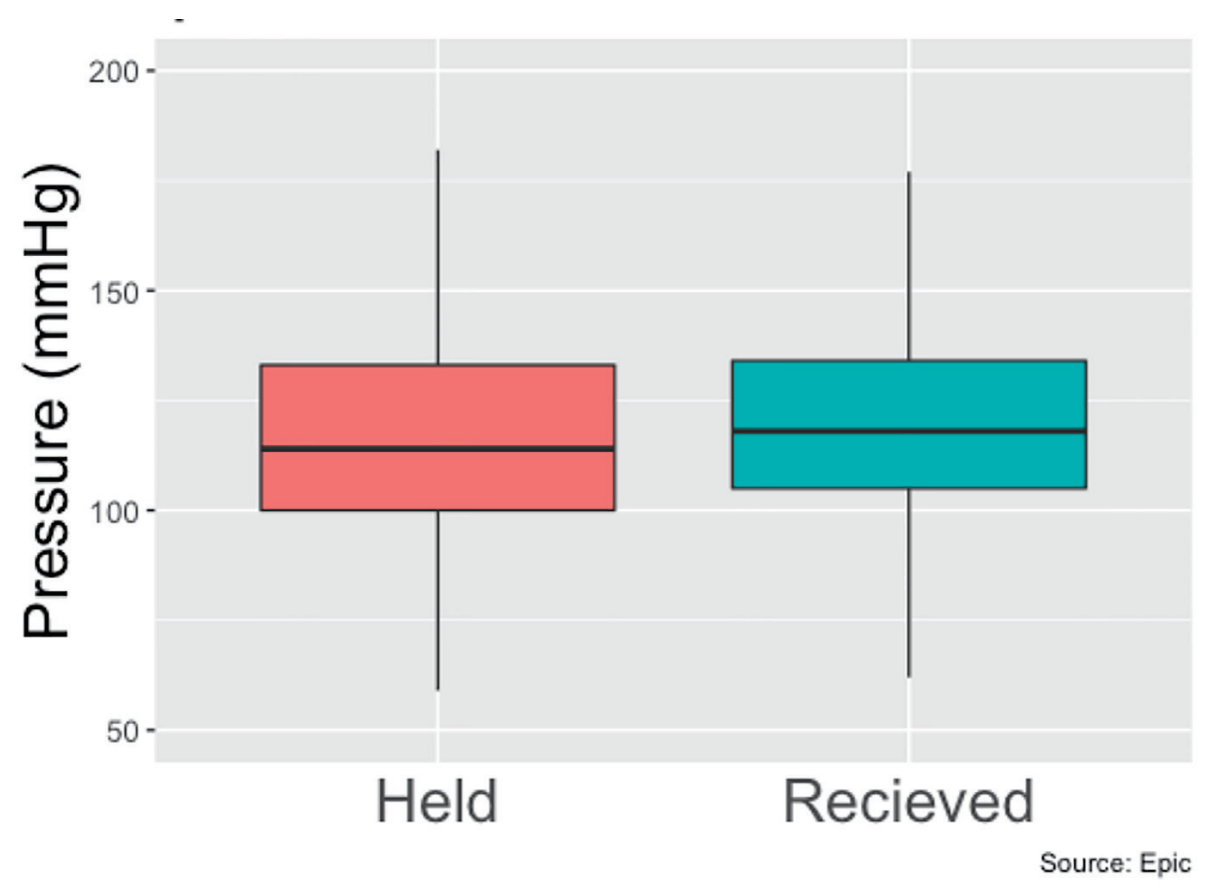

Figure 1. Systolic pressures of patients with held beta-blockers vs. received beta-blockers.

majority of the cost caring for the heart failure patients [2]. The care of patients with heart failure is further complicated by an overall $22.3 \%$ of patients readmitted within 30 days, $33.3 \%$ readmitted within 60 days and $40.2 \%$ readmitted within 90 days [17]. BBs have been shown in multiple studies to reduce mortality and the number and frequency of hospitalizations related to heart failure [1-3]. BBs have also been repeatedly shown to reduce morbidity as evidenced by symptomatic management.
Thus, it is paramount for healthcare providers to pursue medical optimization and to address gaps present in current medical regiments.

It was not the aim of this study to identify the specific reasons for holding $\mathrm{BBs}$ in the inpatient setting, as often the reasoning is not clearly documented; however, literature has cited provider aversion as a common factor. This is owing to the perception of risk associated with providing BBs in con-

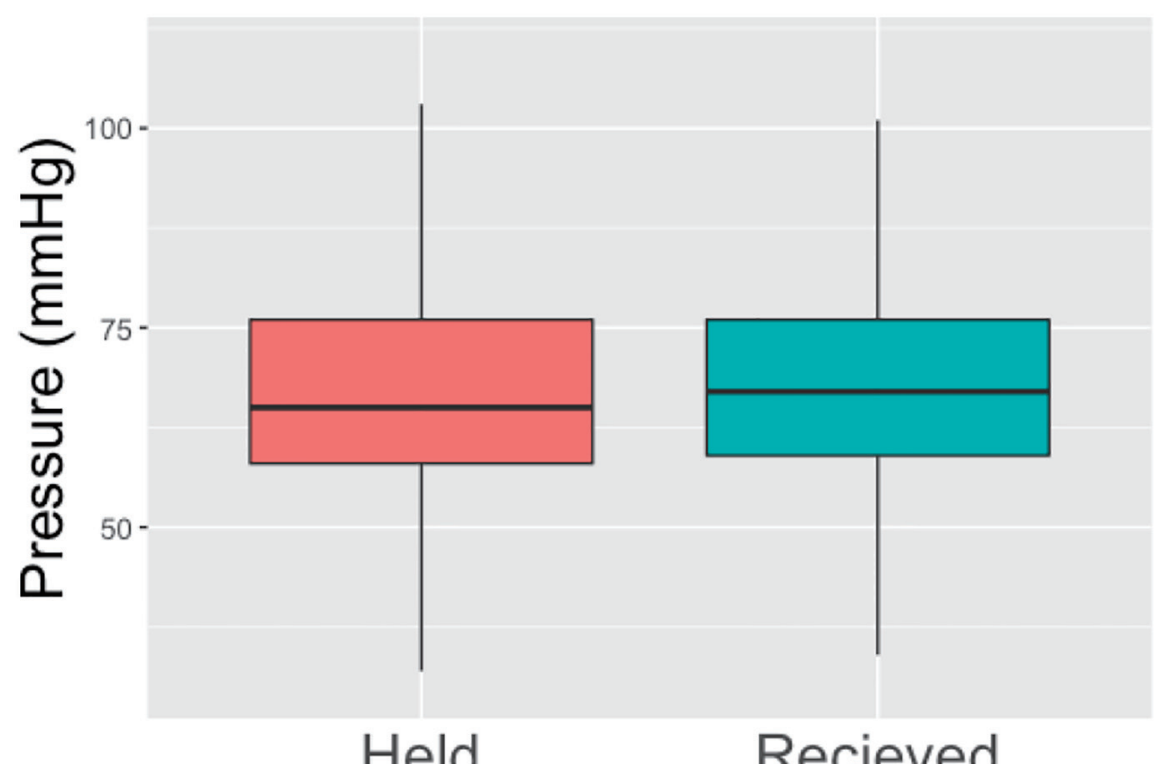

Source: Epic

Figure 2. Diastolic pressure of patients with held beta-blockers vs. received beta-blockers. 


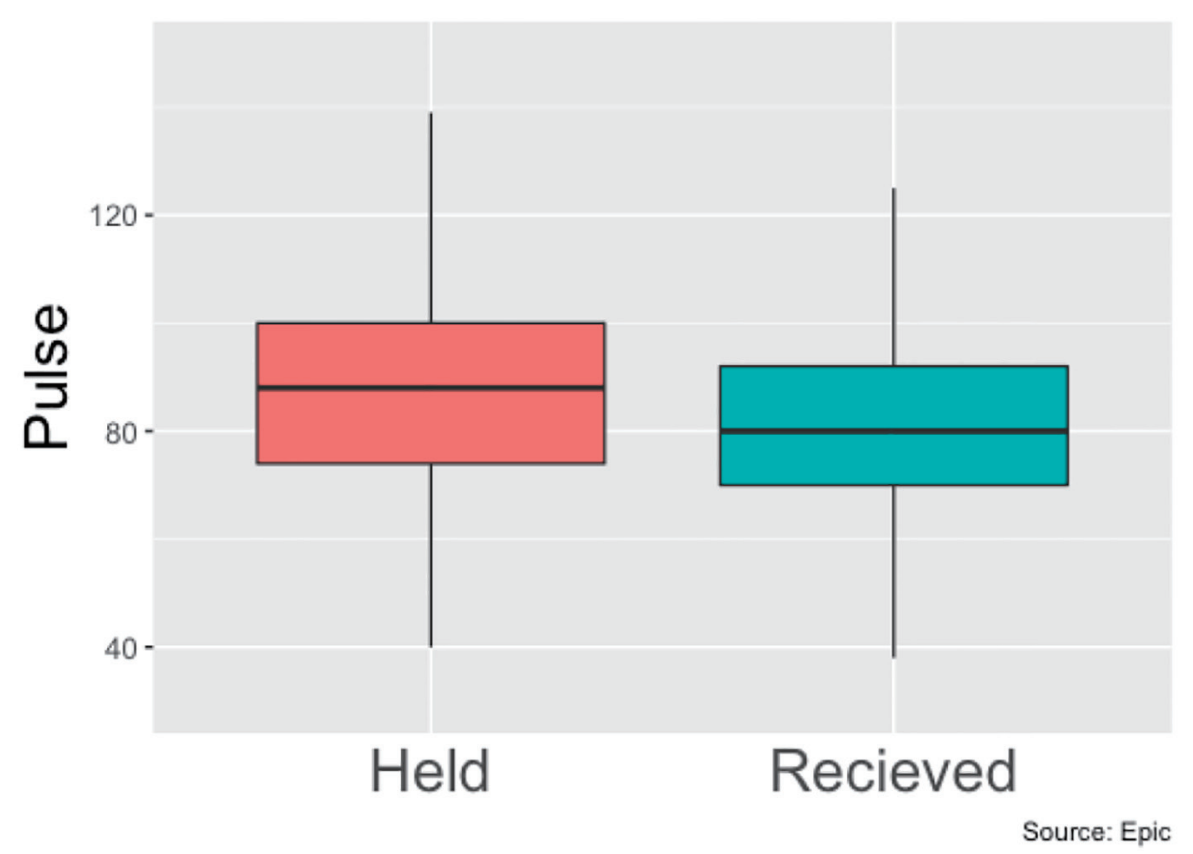

Figure 3. Heart rates means of patients with held beta-blockers vs. received beta-blockers throughout hospital stay.

junction with multiple additional medications, in the setting of hemodynamic measures nearing pre-determined hold parameters, or concern for worsening of acute decompensation due to the negative inotropic effect of the medication [1]. Interestingly, certain hold patterns not related to parameters of vital signs were noted, including a higher tendency for holding $\mathrm{BBs}$ in the hours of the morning when compared to other times during the day and a higher tendency to hold metoprolol than carvedilol. We did not collect data that would determine if patients prescribed metoprolol had more co-morbid conditions, or more advanced heart failure.

According to the literature and current guidelines, it is recommended to delay initiation of BB therapy in the setting of acute decompensated heart failure, if the patient was not taking a $\mathrm{BB}$ prior to admission [18-21]. In this case, it is recommended to first achieve euvolemia, then initiate therapy prior to discharge. Additionally, BBs should not be given in the setting of cardiogenic shock, symptomatic bradycardia, or symptomatic hypotension. If a patient presents with acute decompensated heart failure and has been taking a $\mathrm{BB}$, it is recommended to continue the medication with concurrent diuresis in absence of shock. The B-CONVINCED trial compared two groups of patients with acute decompensated heart failure. One group

Table 1. Hemodynamic Data Among Patients With Held and Received Beta-Blockers

\begin{tabular}{lllll}
\hline & Received & Held & Difference & P value \\
\hline Systolic BP & 120.8 & 117.7 & -3.1 & $<0.001$ \\
Diastolic BP & 68.7 & 67.6 & -1.1 & $<0.001$ \\
Heart rate & 82.4 & 88.6 & 6.2 & $<0.001$ \\
\hline
\end{tabular}

BP: blood pressure. continued to receive $\mathrm{BB}$ therapy at the time of hospital admission, while the other group had BBs held on admission and resumed at time of discharge. The trial compared adherence rates to $\mathrm{BB}$ therapy at 3 months following hospital discharge and noted significant difference in medication adherence rates, with greater long-term adherence in the group with uninterrupted $\mathrm{BB}$ therapy $(\mathrm{P}=0.04)$.

Previous studies have shown similar hold rates of BBs in general medicine and cardiology wards to what this study has found [22]. There have been previous quality improvement projects directed at nursing, physicians and pharmacists to attempt to improve prescription rates for BBs in heart failure patients [22-25]. Our future studies will include examining the hold rates of BB holding practices between different specialties such as cardiology, academic internal medicine, family medicine and hospitalists. We will expand our pharmacologic investigation to the prescribing patters of these different groups regarding angiotensin-converting enzyme (ACE) inhibitors and angiotensin receptor blockers (ARBs). As for quality improvement project, as mentioned previously there have already been several interventions proven to improve prescription rates of BBs. Our next planned intervention will be an intervention in the EMR in conjunction with nursing education. Static and standard hold parameters for BBs cannot supplant clinical judgement when administering BBs to heart failure patients. Modifications to the hold parameters in the EMR may increase the administration rate of BBs. Further training for nursing staff and encouragement of frequent communication with other members of the care team may potentially reduce the frequency of held BBs. Finally, provider guidelines presented as a flag in the EMR upon admission of a patient, may enhance provider awareness of a home BB regimen for patients being admitted. These endeavors may 


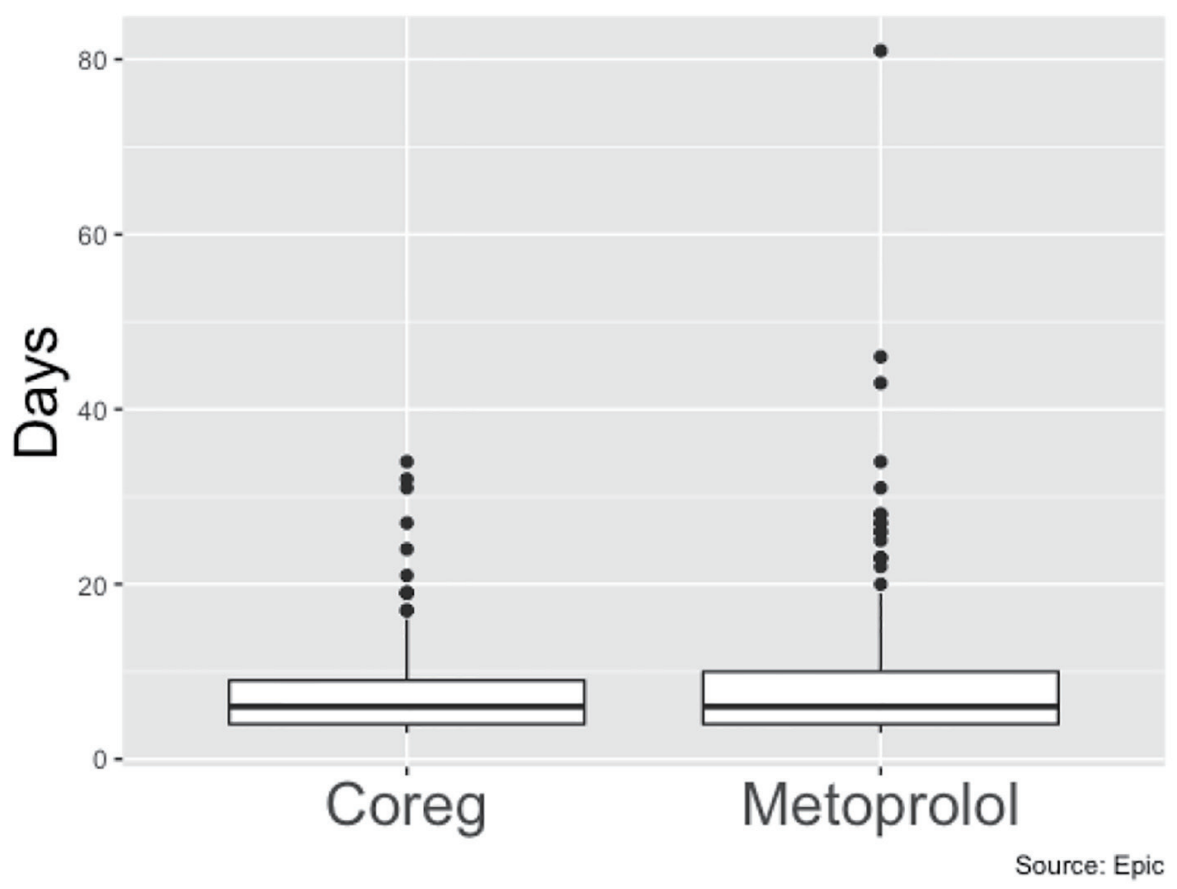

Figure 4. Length of stay (days) of patients on carvedilol vs. patients on metoprolol.

assist physicians to prescribe GDMT to patients with heart failure.

\section{Conclusions}

With growing medical costs and incidence of heart failure in the global population, it is imperative to constantly evaluate and refine our practices for treating this subset of patients in both outpatient and inpatient settings. When it comes to HFrEF patients, the evidence highlighting the benefits of BB behooves us to adopt a culture of BB stewardship, where the goal is identifying situations when it is clinically beneficial to give or hold this therapy. Our study showed that in HFrEF patients, there

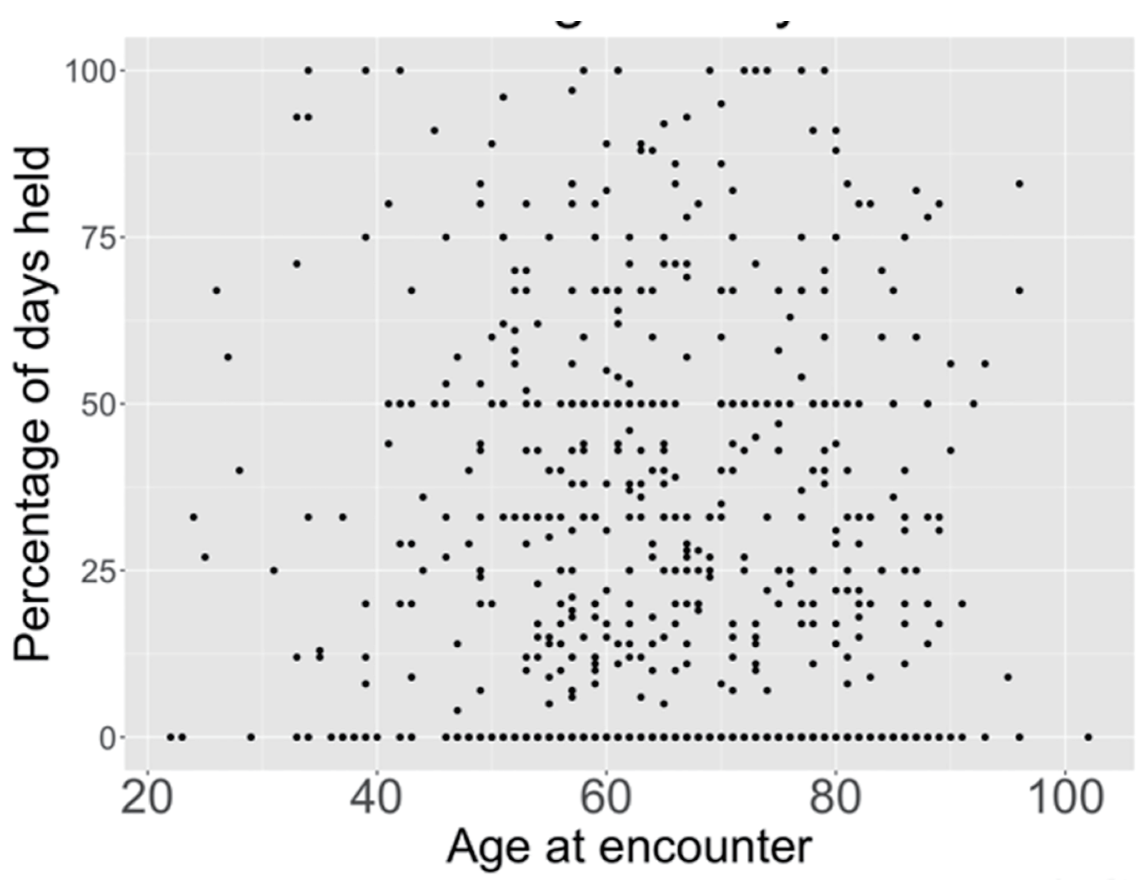

Figure 5. Relationship between age and percentage of days held. 


\section{Differencè in hold raté}

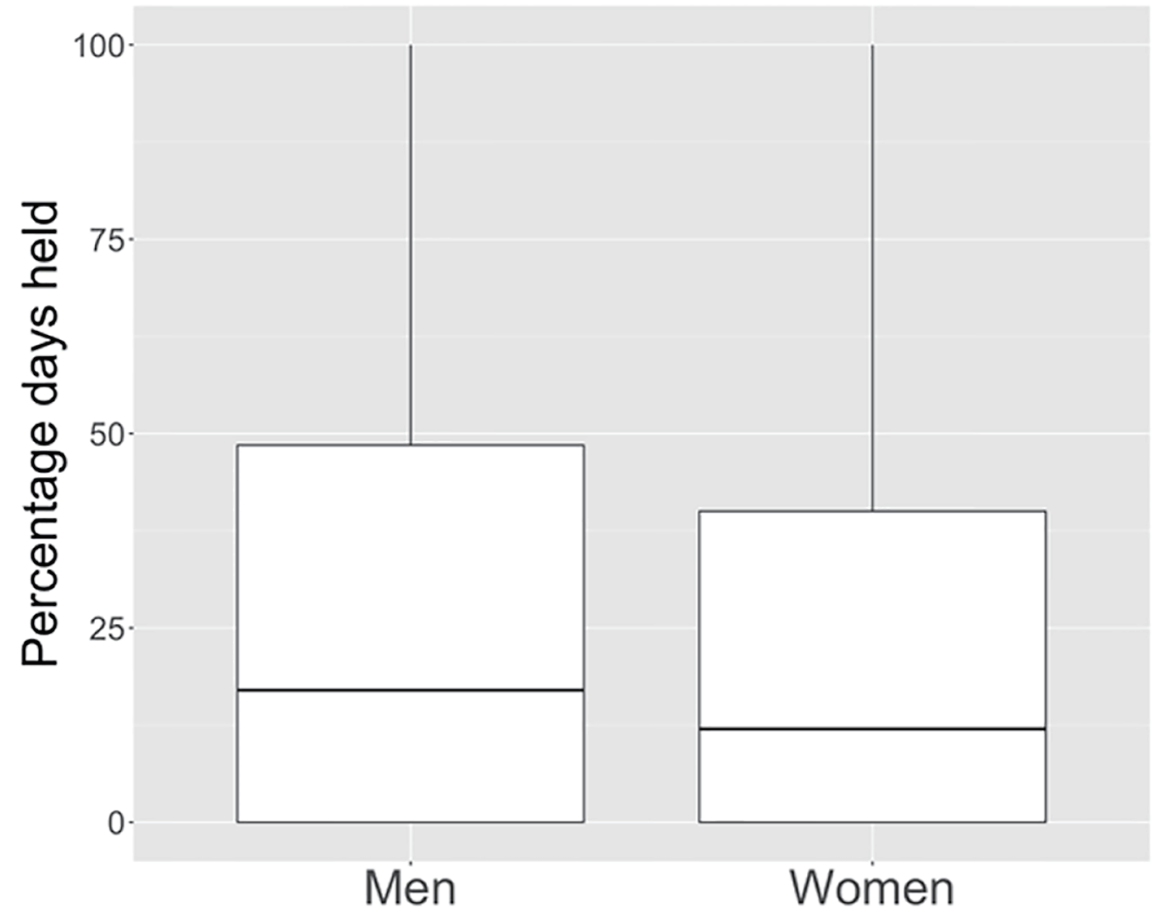

Figure 6. Beta-blocker hold rate in men vs. women as observed in our study.

is prevalence for holding BBs; however, parameters such as blood pressure and heart rate indicate only a minor difference in the hemodynamics of patients receiving or not receiving their $\mathrm{BB}$. The data advocate for $\mathrm{BB}$ administration practices that include clinical picture, close communication with other members of the medical team in conjunction with hold param-

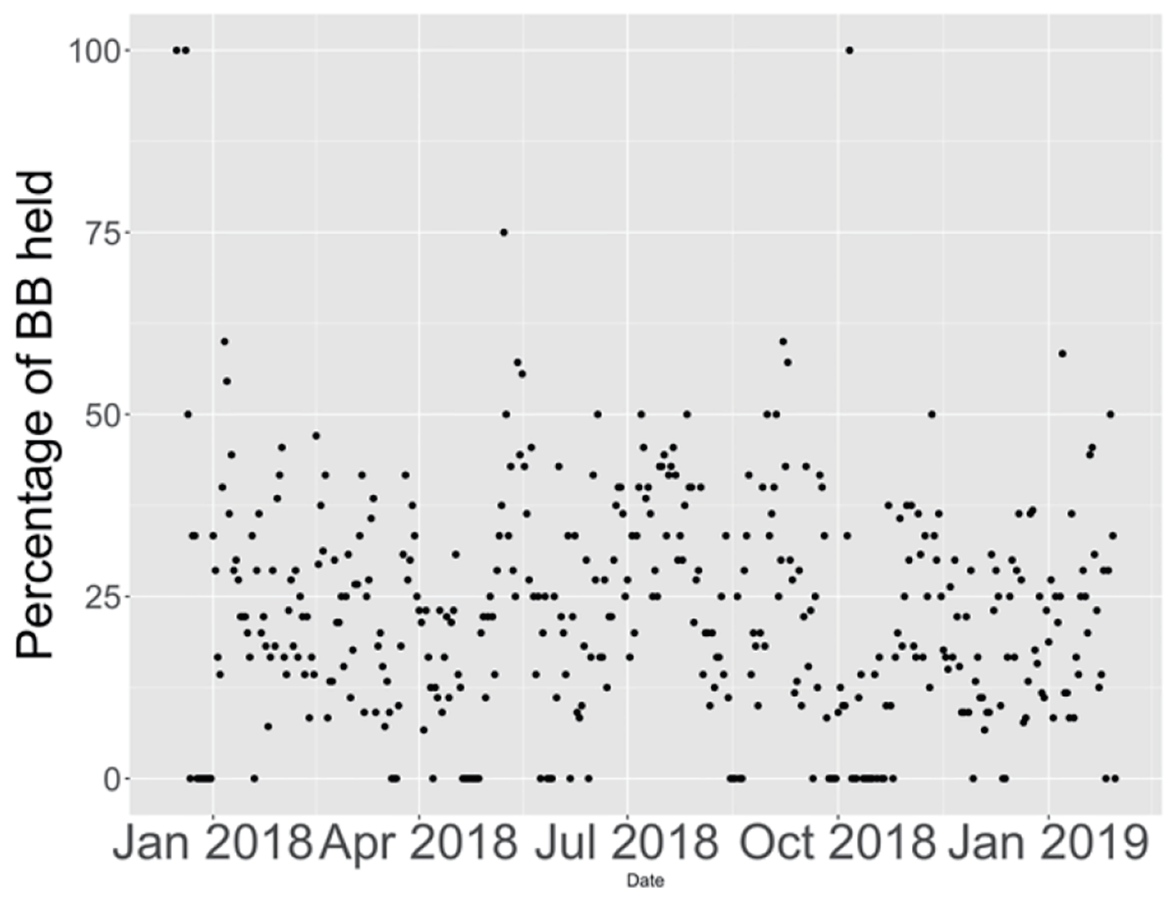

Figure 7. Percentage of beta-blockers held on floors from January 2018 to January 2019. 


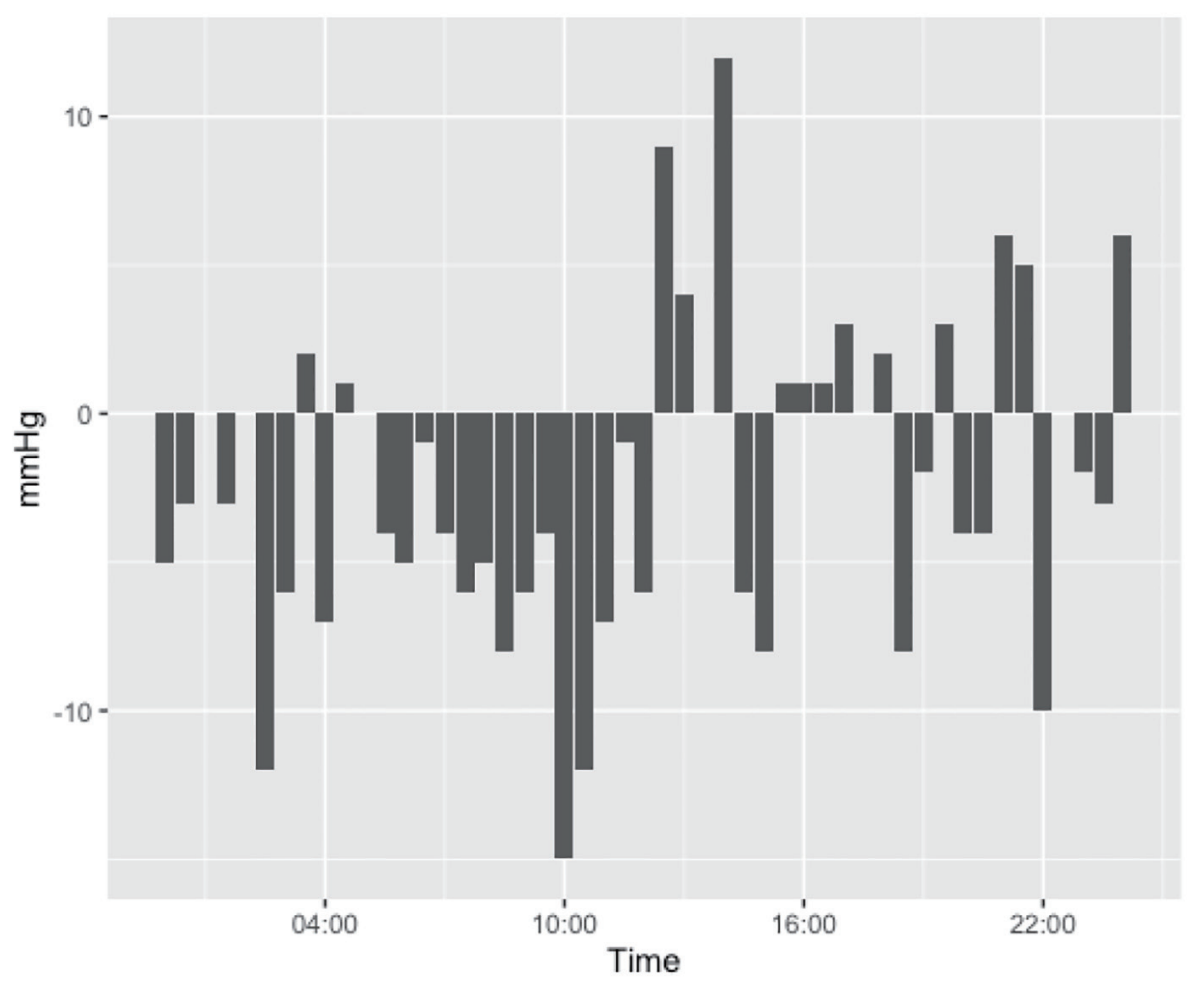

Figure 8. Difference in systolic pressures between patients who had their beta-blockers held against those who received their beta-blocker, divided into 30-min increments throughout the day. Figure was created from data from EPIC.

eters that are appropriate for a patient with heart failure.

\section{Acknowledgments}

None to declare.

\section{Financial Disclosure}

None to declare.

\section{Conflict of Interest}

None to declare.

\section{Informed Consent}

As a retrospective study, there were no patient consents at the time of the encounter.

\section{Author Contributions}

Kimberley O'Dell drafted the manuscript, and was chief editor of the manuscript. Juan Carlos Malpartida and Jacob Mok were instrumental in data collection and data quality control. Rafay Khan and Dr. Patel acted as a mentor, provided meaningful insight on the project, and edited the manuscript.

\section{Data Availability}

Any inquiries regarding supporting data availability of this study should be directed to the corresponding author.

\section{References}

1. The Cardiac Insufficiency Bisoprolol Study II (CIBIS-II): a randomised trial. Lancet. 1999;353(9146):9-13.

2. Effect of metoprolol $\mathrm{CR} / \mathrm{XL}$ in chronic heart failure: Metoprolol CR/XL Randomised Intervention Trial in Congestive Heart Failure (MERIT-HF). Lancet. 1999;353(9169):2001-2007.

3. Packer M, Fowler MB, Roecker EB, Coats AJ, Katus HA, Krum H, Mohacsi P, et al. Effect of carvedilol on the morbidity of patients with severe chronic heart failure: results of the carvedilol prospective randomized cumulative survival (COPERNICUS) study. Circulation. 2002;106(17):2194-2199.

4. Kotecha D. Beta-blockers in high-risk heart failure patients with reduced ejection fraction and moderately-severe renal dysfunction. European Society of Cardiology Congress. 2019. Paris Convention Center, Paris, France. 
5. Yancy CW, Jessup M, Bozkurt B, Butler J, Casey DE, Jr., Drazner MH, Fonarow GC, et al. 2013 ACCF/AHA guideline for the management of heart failure: a report of the American College of Cardiology Foundation/American Heart Association Task Force on Practice Guidelines. J Am Coll Cardiol. 2013;62(16):e147-239.

6. Yancy CW, Jessup M, Bozkurt B, Butler J, Casey DE, Jr., Colvin MM, Drazner MH, et al. 2017 ACC/AHA/HFSA focused update of the $2013 \mathrm{ACCF} / \mathrm{AHA}$ guideline for the management of heart failure: a report of the American College of Cardiology/American Heart Association Task Force on Clinical Practice Guidelines and the Heart Failure Society of America. Circulation. 2017;136(6):e137e161.

7. Cohn JN, Tognoni G, Valsartan Heart Failure Trial I. A randomized trial of the angiotensin-receptor blocker valsartan in chronic heart failure. $\mathrm{N}$ Engl J Med. 2001;345(23):1667-1675.

8. Packer M, Bristow MR, Cohn JN, Colucci WS, Fowler MB, Gilbert EM, Shusterman NH. The effect of carvedilol on morbidity and mortality in patients with chronic heart failure. U.S. Carvedilol Heart Failure Study Group. N Engl J Med. 1996;334(21):1349-1355.

9. Granger CB, McMurray JJ, Yusuf S, Held P, Michelson EL, Olofsson B, Ostergren J, et al. Effects of candesartan in patients with chronic heart failure and reduced leftventricular systolic function intolerant to angiotensinconverting-enzyme inhibitors: the CHARM-Alternative trial. Lancet. 2003;362(9386):772-776.

10. Pitt B, Zannad F, Remme WJ, Cody R, Castaigne A, Perez A, Palensky J, et al. The effect of spironolactone on morbidity and mortality in patients with severe heart failure. Randomized Aldactone Evaluation Study Investigators. N Engl J Med. 1999;341(10):709-717.

11. Zannad F, McMurray JJ, Krum H, van Veldhuisen DJ, Swedberg K, Shi H, Vincent J, et al. Eplerenone in patients with systolic heart failure and mild symptoms. N Engl J Med. 2011;364(1):11-21.

12. Peri-Okonny PA, Mi X, Khariton Y, Patel KK, Thomas L, Fonarow GC, Sharma PP, et al. Target doses of heart failure medical therapy and blood pressure: insights from the CHAMP-HF registry. JACC Heart Fail. 2019;7(4):350358.

13. Mehta PA, McDonagh S, Poole-Wilson PA, GrocottMason R, Dubrey SW. Heart failure in a district general hospital: are target doses of beta-blockers realistic? QJM. 2004;97(3):133-139.

14. Wong GW, Boyda HN, Wright JM. Blood pressure lowering efficacy of beta-1 selective beta blockers for primary hypertension. Cochrane Database Syst Rev. 2016;3:CD007451.
15. Poole-Wilson PA, Swedberg K, Cleland JG, Di Lenarda A, Hanrath P, Komajda M, Lubsen J, et al. Comparison of carvedilol and metoprolol on clinical outcomes in patients with chronic heart failure in the Carvedilol Or Metoprolol European Trial (COMET): randomised controlled trial. Lancet. 2003;362(9377):7-13.

16. Jackson SL, Tong X, King RJ, Loustalot F, Hong Y, Ritchey MD. National Burden of Heart Failure Events in the United States, 2006 to 2014. Circ Heart Fail. 2018;11(12):e004873.

17. Kilgore M, Patel HK, Kielhorn A, Maya JF, Sharma P. Economic burden of hospitalizations of Medicare beneficiaries with heart failure. Risk Manag Healthc Policy. 2017;10:63-70.

18. Butler J, Young JB, Abraham WT, Bourge RC, Adams KF, Jr., Clare R, O'Connor C, et al. Beta-blocker use and outcomes among hospitalized heart failure patients. J Am Coll Cardiol. 2006;47(12):2462-2469.

19. Metra M, Torp-Pedersen C, Cleland JG, Di Lenarda A, Komajda M, Remme WJ, Dei Cas L, et al. Should betablocker therapy be reduced or withdrawn after an episode of decompensated heart failure? Results from COMET. Eur J Heart Fail. 2007;9(9):901-909.

20. Fonarow GC, Abraham WT, Albert NM, Stough WG, Gheorghiade M, Greenberg BH, O'Connor CM, et al. Influence of beta-blocker continuation or withdrawal on outcomes in patients hospitalized with heart failure: findings from the OPTIMIZE-HF program. J Am Coll Cardiol. 2008;52(3):190-199.

21. Orso F, Baldasseroni S, Fabbri G, Gonzini L, Lucci D, D'Ambrosi C, Gobbi M, et al. Role of beta-blockers in patients admitted for worsening heart failure in a real world setting: data from the Italian Survey on Acute Heart Failure. Eur J Heart Fail. 2009;11(1):77-84.

22. Chua CC, Hutchinson A, Tacey M, Parikh S, Lim WK, Aboltins C. A physician targeted intervention improves prescribing in chronic heart failure in general medical units. BMC Health Serv Res. 2018;18(1):206.

23. Fedyk-Lukasik M, Wizner B, Opolski G, Zdrojewski T, Czech M, Dubiel JS, Marchel M, et al. Quality of care of hospitalised patients with heart failure in Poland in 2013: results of the second nationwide survey. Kardiol Pol. 2017;75(6):527-534.

24. Hickey A, Suna J, Marquart L, Denaro C, Javorsky G, Munns A, Mudge A, et al. Improving medication titration in heart failure by embedding a structured medication titration plan. Int J Cardiol. 2016;224:99-106.

25. Milfred-LaForest SK, Gee JA, Pugacz AM, Pina IL, Hoover DM, Wenzell RC, Felton A, et al. Heart failure transitions of care: a pharmacist-led post-discharge pilot experience. Prog Cardiovasc Dis. 2017;60(2):249-258. 